\title{
Efeito de dietas que contêm cana-de-açúcar ou silagem de milho sobre as características das carcaças de novilhos confinados
}

\author{
Effect of diets containing sugar-cane or corn silage on carcass \\ characteristics of feedlot steers
}

\author{
Ivan Luiz Brondani ${ }^{1}$ João Restle ${ }^{2}$ Miguelangelo Ziegler Arboitte ${ }^{3}$ \\ Luís Fernando Glasenapp de Menezes $^{4}$ Dari Celestino Alves Filho $^{5}$ \\ Gláucia Azevedo do Amaral ${ }^{6}$ Raul Dirceu Pazdiora $^{7}$
}

\section{RESUMO}

Este estudo teve o objetivo de avaliar as características quantitativas e qualitativas da carcaça e da carne de doze novilhos Charoles, submetidos a dois tratamentos alimentares durante a fase de terminação em confinamento, aos 30 meses de idade: TC- cana-de-açúcar (Saccharum officinarum ssp.) $e$ TM- silagem de milho (Zea mays), compondo 43,65 e 45,14\% da matéria seca $(M S)$ da dieta, respectivamente. A dieta oferecida foi isonitrogenada, com $11,76 \%$ proteína bruta na MS, o concentrado foi constituído de grão de sorgo moído, farelo de arroz desengordurado e farelo de soja, de igual composição para os tratamentos, com adição de uréia junto ao TC. Os animais foram mantidos em regime de confinamento até que a média dos tratamentos atingiu o peso de abate de $420 \mathrm{~kg}$ (TC - 110 dias e TS - 88 dias). O peso de carcaça quente foi 214,23 e 222,23 kg para TC e TS, respectivamente. A percentagem de rendimento de carcaça quente foi de 50,71 e $52,60 \%,(P=0,0612)$ e a de carcaça fria de 50,38 e 52,24\% $(P=0,0478)$. A quebra no resfriamento não diferiu entre os tratamentos alimentares $(P=0,7901)$; comportamento igual obteve-se para conformação $(P=0,3334)$, espessura de gordura subcutânea $(P=0,9262)$, área do músculo Longissimus dorsi em $\mathrm{kg}$ e em \% ( $P=0,5834 ; P=0,2094$, respectivamente $)$. As carcaças dos novilhos do TC apresentaram maior percentagem de corte serrote $(50,04 \mathrm{vs} .49,36 \%, P=0,0984)$. Os cortes dianteiro e costilhar não foram diferentes $(P=0,9963 e$ $P=0,1295$ ) entre os tratamentos. A percentagem de músculo foi superior para TS em relação ao TC, de 70,67 e 68,08\% $(P=0,0142)$, comportamento similar ao da percentagem de gordura na carcaça 11,92 e $15,58 \%(P=0,0137)$ para $T C e$ $T S$, respectivamente.

Palavras-chave: carne; Charolês, gordura, músculo, osso.

\begin{abstract}
The objective of the experiment was to evaluate carcass and meat quantitative and qualitative characteristics of twelve Charolais steers with 30 months of age, submitted to two food treatments during feedlot finishing phase: Tc-sugar-cane (Saccharum officinarum ssp.) and TM-corn silage (Zea mays), composing 43.65 and $45.14 \%$ of diet is dry matter (DM), respectively. The diet offered had $11.76 \%$ of crude protein on $D M$, the concentrate was constituted of grounded sorghum grain, defatted rice bran and soybean bran, with equal composition for the treatments, with urea addition for TC. The animals were kept in feedlot until average slaughter weight was of $420 \mathrm{~kg}$ (TC - 110 days and TS - 88 days). Hot carcass weight was 214.23 and $222.23 \mathrm{~kg}$ for TC and TS, respectively. Hot carcass dressing percentage was of 50.71 and $52.60 \%$, $(P=.0612)$ and cold carcass dressing percentage was of 50.38 and $52.24 \%(P=.0478)$. The chilling loss did not differ between the alimentary treatments $(P=.7901)$; equal behavior was for conformation $(P=.3334)$, thickness of subcutaneous fat $(P=.9262)$, area of the Longissimus dorsi muscle in $\mathrm{kg}$ and \% $(P=.5834 ; P=.2094$, respectively). TC steers showed carcasses with higher sawcut percentage (50.04 vs. 49.36\%, $P=.0984)$. Forequarter and sidecut, not differed $(P=.9963$ and $P=.1295)$ between treatments. Muscle percentage was superior for TS in relation to the TC, of 70.67 and $68.08 \%(P=0.0142)$, the same for carcass fat percentage, being 11.92 and $15.58 \%(P=.0137)$ for $T C$ and $T S$, respectively.
\end{abstract}

Key words: bone, Charolais, fat, meat, muscle.

\section{INTRODUÇÃO}

Apesar de o número de animais terminados em confinamento, ter aumentado nos últimos anos,

\footnotetext{
${ }^{1}$ Universidade Federal de Santa Maria (UFSM). Santa Maria, RS, Brasil. E - mail: brondani@ccr.ufsm.br.

${ }^{2}$ Universidade Federal de Góias (UFG). Goiânia, GO, Brasil.

${ }^{3}$ Departamento de Zootecnia, UFSM. Santa Maria, RS, Brasil. E - mail: marboitte@sulmail.com.br

${ }^{4}$ UFSM. Santa Maria, RS, Brasil.

${ }^{5}$ Departamento de Zootecnia, UFSM, Santa Maria, RS, Brasil.

${ }^{6}$ Curso de Zootecnia, UFSM. Santa Maria, RS, Brasil

${ }^{7}$ Curso de Medicina Veterinária, UFSM. Santa Maria, RS, Brasil.
} 
pode-se ainda afirmar que a base da alimentação para a terminação de bovinos no Brasil são as pastagens, cultivadas ou nativas. $\mathrm{O}$ incremento anual de animais confinados traz a necessidade de mais informações sobre os alimentos, a qualidade e quantidade a serem utilizados para a alimentação de bovinos na fase de terminação, propiciando carcaças com melhores características.

A cana-de-açúcar como alimento volumoso para ruminantes, segundo CARMO et al. (2001) apresenta baixo valor nutritivo, limitado pela baixa digestão da parede celular, que contribui com pouca energia metabolizável para o animal, além de reduzida eficiência dos açúcares solúveis. Também é limitado pela menor quantidade de proteína bruta $(\mathrm{PB})$, nutrientes digestíveis totais (NDT) e de menor digestibilidade em relação à da silagem de milho (LANA, 2000). A silagem de milho, devido principalmente à presença de grãos na matéria seca (MS), pode ter sua qualidade melhorada no material ensilado (BRONDANI, 1989). Mesmo com qualidade inferior, a cana-de-açúcar é largamente utilizada, seja na forma in natura, hidrolisada ou de bagaço nos confinamentos brasileiros, por ser um produto de fácil produção e aquisição.

Resultados com o uso da silagem de milho mostram variações quanto às características de carcaça de novilhos terminados, não somente em função das características da silagem, mas também à associação desse uso às características do animal.

Novilhos da raça Charolês, alimentados com cana-de-açúcar foram relatados por RESTLE et al. (1995), que observaram rendimento de carcaça quente de $52,43 \%$, quebra no resfriamento de $1,46 \%$, apesar da pouca espessura de gordura subcutânea $(2,7 \mathrm{~mm})$. Percentagem de corte serrote de $50,11 \%$ e costilhar de $13,62 \%$ foram registrados por MOLETTA \& RESTLE (1996).

O presente trabalho teve por objetivo avaliar os efeitos da silagem de milho ou cana-de-açúcar integral sobre as características quantitativas e qualitativas de carcaça de novilhos da raça Charolês.

\section{MATERIAL E MÉTODOS}

Foram estudadas 12 carcaças de novilhos da raça Charolês, com três anos de idade, terminados em regime de confinamento. Os animais foram abatidos, quando os tratamentos atingiram o peso médio vivo mínimo de $420 \mathrm{~kg}$. As carcaças foram divididas em dois grupos conforme o tipo de alimento volumoso da dieta: TC - novilhos alimentados com cana-de-açúcar (Saccharum officinarum ssp.) mais uréia, participando com 43,65\% da MS da dieta; TS - novilhos alimentados silagem de milho (Zea mays), participando com 45,14\% da MS da dieta. O concentrado foi composto por grão de sorgo triturado, farelo de arroz desengordurado e farelo de soja, para os dois tratamentos. O teor de PB das dietas foi de $11,76 \%$. Para que as dietas fossem isoprotéicas a uréia foi adicionada no momento do arraçoamento dos animais do tratamento TC.

Os animais foram abatidos segundo a técnica de rotina do frigorífico, e o processo de avaliação das carcaças seguiu as normas descritas por MÜLLER (1987). Após o abate e antes do resfriamento, foi obtido o peso de carcaça quente (PCQ), determinando-se o seu rendimento. Resfriadas por 24 horas, a $1^{\circ} \mathrm{C}$, pesaramse as carcaças para a obtenção do peso de carcaça fria e determinou-se a percentagem de quebra no resfriamento, além do rendimento de carcaça fria. As avaliações da conformação e maturidade fisiológica das carcaças foram obtidas seguindo metodologia sugerida por MÜLLER (1987).

Na meia carcaça esquerda, foram separados e pesados os cortes comerciais (serrote ou traseiro, dianteiro e costilhar), cujos pesos foram convertidos em percentagens com relação ao peso de carcaça fria. $\mathrm{Na}$ meia carcaça direita, foram realizadas avaliações métricas do comprimento de carcaça, comprimento da perna, espessura do coxão e perímetro do braço. Após, ainda na meia carcaça direita, realizou-se um corte transversal entre $12^{\mathrm{a}}$ e $13^{\mathrm{a}}$ costelas, e foi medida a espessura de gordura subcutânea e exposto o músculo Longissimus dorsi, para a obtenção da área do Longissimus dorsi $\mathrm{em} \mathrm{cm}^{2}$ (AOL, $\mathrm{cm}^{2}$ ) e expressa em relação a $100 \mathrm{~kg}$ de carcaça fria (AOL\%). No músculo Longissimus dorsi, foram avaliados o marmoreio, cor e textura, conforme técnica descrita por MÜLLER (1987) A avaliação da composição física da carcaça em músculo, gordura e osso foi realizada utilizando-se a secção de lombo compreendida entre a $10^{\mathrm{a}}$ e $12^{\mathrm{a}}$ costelas, conforme técnica descrita por HANKINS \& HOWE (1946) e adaptada por MÜLLER (1973).

O delineamento experimental utilizado foi o inteiramente casualizado, com dois tratamentos e seis repetições. Os dados foram submetidos à análise de variância e teste $\mathrm{F}$, em nível de $5 \%$, por intermédio do programa estatístico SAS (2001). Realizou-se a correlação de Pearson entre as variáveis estudadas. O peso inicial dos novilhos foi utilizado como covariável.

\section{RESULTADOS E DISCUSSÃO}

Na tabela 1, são apresentados os dados relativos a peso de fazenda, rendimento de carcaça quente e fria, percentagem de quebra no resfriamento, conformação, maturidade fisiológica, comprimento de 
Tabela 1 - Resultados médios ajustados peso inicial para peso de fazenda, peso de carcaça quente e fria, rendimento de carcaça quente e fria, quebra no resfriamento, conformação, maturidade fisiológica, comprimento de carcaça, de perna, perímetro do braço e espessura do coxão.

\begin{tabular}{|c|c|c|c|c|}
\hline \multirow{2}{*}{ Variáveis } & \multicolumn{2}{|c|}{ Dietas } & \multirow{2}{*}{ Probabilidade } & \multirow{2}{*}{ Erro } \\
\hline & $\mathrm{TC}$ & TS & & \\
\hline Peso de fazenda, $\mathrm{kg}$ & 421,33 & 422,67 & 0,9475 & 13,96 \\
\hline Peso de carcaça quente,kg & 214,23 & 222,23 & 0,5440 & 9,01 \\
\hline Peso de carcaça fria, $\mathrm{kg}$ & 212,83 & 220,70 & 0,5416 & 8,80 \\
\hline Rendimento de carcaça quente, $\%$ & 50,71 & 52,60 & 0,0612 & 0,63 \\
\hline Rendimento de carcaça fria, $\%$ & 50,38 & 52,24 & 0,0478 & 0,58 \\
\hline Quebra no resfriamento, $\%$ & 0,63 & 0,68 & 0,7901 & 0,13 \\
\hline Conformação, pontos* & 8,83 & 9,67 & 0,3334 & 0,58 \\
\hline Maturidade fisiológica & 10,50 & 11,50 & 0,0101 & 0,22 \\
\hline Comprimento de carcaça, cm & 121,83 & 121,33 & 0,7986 & 1,35 \\
\hline Comprimento de perna, $\mathrm{cm}$ & 65,33 & 65,58 & 0,8496 & 0,91 \\
\hline Perímetro de braço, $\mathrm{cm}$ & 35,58 & 34,83 & 0,5452 & 0,85 \\
\hline Espessura de coxão, cm & 24,17 & 23,25 & 0,2475 & 0,53 \\
\hline
\end{tabular}

$* 8=$ Regular típica; $9=$ Regular mais; $10=$ Boa menos

carcaça e perna, perímetro do braço e espessura do coxão.

O tratamento TS apresentou maior rendimento de carcaça quente, de 52,60 e TC de 50,71\% $(\mathrm{P}=0,0612)$, fato que pode ser atribuído à maior digestibilidade da silagem de milho (44,4 vs. 33,6\%). Como conseqüência, acarretou maior permanência da cana-de-açúcar no trato digestivo, ocasionando maior volume ruminal e interferindo no rendimento de carcaça. FRANZOLIN et al. (2000) observaram baixa produtividade de animais alimentados com dietas à base de cana-de-açúcar. Por outro lado, a silagem de milho, além de apresentar uma melhor digestibilidade, pela participação de grãos, contribuiu para uma maior taxa de desaparecimento.

Os resultados do rendimento de carcaça observados no experimento foram superiores àqueles relatados por SOUZA (1983), de 48,17\% em novilhos e por RESTLE et al. (2003), com valor de 49,00\%, em vacas da raça Charolês, alimentadas em confinamento.

Rendimentos de carcaça de $51 \%$ em novilhos Charolês alimentados com cana de açúcar na fração volumosa da dieta são relatados por MOLETTA \& RESTLE (1996). Ao alimentar, com cana de açúcar, novilhos mestiços Charolês X Nelore, RESTLE et al. (1994) relatam rendimentos de carcaça fria de 52,1\%, semelhantes ao rendimento encontrado neste experimento e inferiores aos registrados por PATE (1981) e KEPLIN et al. (1986), que encontraram valores de 55,6 e 54.2\%, em novilhos confinados com dieta à base de cana-de-açúcar.

A percentagem de quebra no resfriamento (Qresf \%) não apresentou diferença $(\mathrm{P}=0,7901)$ entre os dois tratamentos. No presente experimento, a correlação entre a Qresf \% e a espessura de gordura subcutânea (EGS) foi de 0,31 ( $\mathrm{P}=0,3205$ ), indicando que, à medida que a EGS aumentou, a Qresf \% não foi afetada. Era de se esperar uma correlação mais alta e significativa entre estas duas características, devido à associação entre perdas de líquidos no momento do resfriamento das carcaças e a EGS que protege a carcaça do frio, retendo a exsudação dos líquidos constituintes da carcaça. ARBOITTE et al. (2004) relataram que a gordura que recobre a carcaça atua como um isolante reduzindo as perdas por desidratação. De maneira geral, carcaças com maior EGS apresentam menor quebra durante o resfriamento.

Percentagens de quebra no resfriamento superiores foram registradas por MOLETTA \& RESTLE (1996) e por SOUZA (1983), de 1,83 e 1,59\%, obtidos de carcaças de novilhos confinados, cujas EGS foram de 1,16 e $2,88 \mathrm{~mm}$, respectivamente.

Os resultados observados para a conformação (Conf), classificando com escore médio 8,83 (regular mais) para TC e escore médio 9,67 (boa menos) para TS, não mostraram diferença significativa entre os tratamentos $(\mathrm{P}=0,3334)$. Esses valores são considerados baixos, se comparados com os apresentados por MÜLLER et al. (1980), e próximos dos observados por RESTLE et al. (1994), que estudaram carcaças de novilhos cruzados CharolêsNelore e registraram conformação classificada como boa (10,0 pontos). Porém, ABAID (1981), estudando carcaças de novilhos de 30 a 48 meses de idade, com peso de $208,85 \mathrm{~kg}$, observaram conformações classificadas como regular. Esse resultado foi 
observado por MORAES (1982), no estudo de carcaças de novilhos Charolês, com peso de abate de $403,00 \mathrm{~kg}$. Quanto ao comprimento de carcaça (CCarc), os resultados do TC e TS mostraram-se similares, com valores de 121,8 e 121,3cm ( $\mathrm{P}=0,7986)$, respectivamente. A média do CCarc dos tratamentos foi de $121,6 \mathrm{~cm}$, sendo similar aos resultados obtidos por RESTLE et al. (1994), quando estudaram carcaças de novilhos abatidos aos 25 meses e por ABAID (1981) em carcaças de novilhos que registraram 121,1 e 121,4 cm, abatidos aos 30 e 48 meses, respectivamente, mas essa média foi inferior aos valores encontrados por RESTLE et al. (1995) e por MOLETTA \& RESTLE (1996), que registraram 125,0 e $124,4 \mathrm{~cm}$, respectivamente, em carcaças de novilhos Charolês.

O comprimento de perna (Cpern) não diferiu entre TC e TS, sendo os valores 65,3 e $65,6 \mathrm{~cm}$ ( $\mathrm{P}=0,8496)$, valores similares aos citados por MOLETTA \& RESTLE (1996) e MÜLLER et al. (1980), que registraram 65,6 e $65,9 \mathrm{~cm}$, respectivamente. Porém foram inferiores aos encontrados por RESTLE et al. (1996), de 70,3cm.

$\mathrm{O}$ perímetro do braço (PBrac) não diferiu entre os tratamentos $(\mathrm{P}=0,5452)$, concordando com os resultados obtidos por RESTLE et al. (1996) e por MOLETTA\& RESTLE (1996), em carcaças de novilhos, os quais observaram valores de 35,3 e $35,2 \mathrm{~cm}$, respectivamente.

As medidas métricas de Ccarc., CPern e PBrac. demonstram ser influenciadas mais pela raça estudada e idade dos novilhos, do que pelo tipo de volumoso oferecido na dieta.

A espessura do coxão (Ecox) não foi diferente entre os tratamentos estudados $(\mathrm{P}=0,2475)$. Por ser uma característica que auxilia na expressão da musculosidade, a silagem de milho não conseguiu diferenciá-la, apesar de apresentar melhor digestibilidade em relação à cana de açúcar. Os valores observados mostram-se similares aos encontrados por RESTLE et al. (1994), de 23,1 cm, porém inferiores, quando comparados com os de RESTLE et al. (1996), que observaram valores de $25,6 \mathrm{~cm}$.

Na tabela 2, são apresentados resultados médios, ajustados para peso inicial, para a espessura de gordura subcutânea (EGS), área do músculo Longissimus dorsi, área do músculo Longissimus dorsi $\%$, cor, textura, marmoreio, percentagens de cortes serrote, dianteiro e costilhar, percentagens de músculo, osso e gordura.

No estudo da EGS, os dois tratamentos apresentaram valores similares 2,40 e 2,46 $(\mathrm{P}=0,9262)$ para TC e TS, podendo esses graus de acabamento serem explicados em parte devido ao peso de abate similar dos animais (421,33kg no TC e 422,67kg no TS). Estes valores podem ser considerados baixos em relação ao ideal exigido pelo mercado ( $3 \mathrm{~mm})$, sendo importante devido à idade com a qual os animais foram abatidos. Vários trabalhos, têm demonstrado que a EGS presente na carcaça está muito correlacionada com o nível energético oferecido na dieta aos ruminantes. Isto é verdadeiro em função do aumento da demanda energética, à medida que os bovinos aumentam os seus pesos.

As EGS, relatadas neste experimento, tiveram resultados superiores as encontradas por MÜLLER et al. (1980) e por MOLETTA \& RESTLE (1996) que registraram valores de 1,55 e 1,16 mm, respectivamente. Porém, similares aos observados por RESTLE et al. (1994), sendo 3,1 mm e RESTLE et al. (1995), 2,7 mm.

A área do músculo Longissimus dorsi, seja em $\mathrm{cm}^{2}$, como em \% não diferiu ( $\mathrm{P}=0,5834$ e $\left.\mathrm{P}=0,2094\right)$ entre os tratamentos TC e TS. Os resultados $\left(\mathrm{cm}^{2}\right)$ foram semelhantes àqueles obtidos por MOLETTA \& RESTLE (1996), que registraram 67,09 $\mathrm{cm}^{2} \mathrm{em}$ carcaças de novilhos Charolês, com 436,0kg de peso de abate.

Com relação à percentagem de corte serrote, as carcaças do TC $(50,04 \%)$ mostram-se superiores às do TS $(49,36 \% ; \mathrm{P}=0,0984)$. Apesar de as diferenças numéricas serem pequenas, concordam com o resultado obtido por MOLETTA \& RESTLE et al. (1996), que obtiveram $50,11 \%$, no entanto, mostraram-se superiores aqueles observados por RESTLE et al. (1996) que registraram 47,9\% e por RESTLE et al. (1995), que obtiveram 48,02\%. Quanto às percentagens de corte dianteiro e costilhar, também não foram verificadas diferenças ( $\mathrm{P}=0,9963$ e $\mathrm{P}=0,1295)$ entre TC e TS.

Analisando a composição física da carcaça, observou-se que as carcaças do TS apresentaram maior percentagem de músculo ( 70,67 vs $68,08 \% ; \mathrm{P}=0,0142)$ e menor de gordura (26,17 vs. $33,27 \%$; $\mathrm{P}=0,0555)$, quando comparadas com as TC, mostrando, porém, similaridade na percentagem de osso $(\mathrm{P}=0,3700)$.

Carcaças com maior quantidade de músculo e menor quantidade de gordura são ideais, pois nestas, o toalete é menos acentuado, diminuindo o desperdício e aumentando o rendimento da carcaça. Também o mercado consumidor prefere carnes com menor quantidade de gordura, existindo relação entre a gordura consumida pelas pessoas e problemas cardiovasculares.

Diferente das medidas que expressam a musculosidade, a porcentagem de músculo mostrouse superior no tratamento que continha o volumoso de 
Tabela 2 - Resultados médios, ajustados para peso inicial, obtidos para a espessura de gordura subcutânea, área do músculo Longissimus dorsi, área do músculo Longissimus dorsi (\%), cor, textura, marmoreio, percentagens de cortes serrote, dianteiro e costilhar, percentagens de músculo, osso e gordura.

\begin{tabular}{|c|c|c|c|c|}
\hline \multirow{2}{*}{ Variáveis } & \multicolumn{2}{|c|}{ Dietas } & \multirow{2}{*}{ Probabilidade } & \multirow{2}{*}{ Erro } \\
\hline & TC & TS & & \\
\hline Espessura de gordura,mm & 2,40 & 2,46 & 0,9262 & 0,43 \\
\hline Área do músculo Longissimus dorsis, $\mathrm{cm}^{2}$ & 67,52 & 64,30 & 0,5834 & 4,01 \\
\hline Área do músculo Longissimus dorsis, \% & 31,60 & 29,18 & 0,141 & 4.01 \\
\hline Cor* & 5,50 & 4,67 & 0,3813 & 0,64 \\
\hline Textura** & 3,50 & 4,17 & 0,0379 & 0,20 \\
\hline Marmoreio $* * *$ & 6,50 & 4,00 & 0,1114 & 1,01 \\
\hline Corte serrote, $\%$ & 50,04 & 49,36 & 0,0984 & 0,26 \\
\hline Corte dianteiro, $\%$ & 36,72 & 36,72 & 0,9963 & 0,24 \\
\hline Corte costilhar, $\%$ & 13,24 & 13,92 & 0,1295 & 0,29 \\
\hline Músculo, \% & 68,08 & 70,67 & 0,0142 & 0,62 \\
\hline Osso, $\%$ & 14,14 & 14,71 & 0,3700 & 0,43 \\
\hline Gordura, $\%$ & 15,58 & 11,92 & 0,0137 & 0,87 \\
\hline
\end{tabular}

*4=vermelha; 5=vermelho vivo;

$* * 3=$ levemente grosseira; $4=$ fina;

$* * * 4=$ leve menos; $5=$ leve; $6=$ leve mais; $7=$ pequeno menos;

melhor qualidade, que apresentou maior digestibilidade, fazendo a diferença justamente na porção mais importante da carcaça.

A menor percentagem de músculo e o maior percentual de gordura nas carcaças do TC, deve-se principalmente pela maior permanência dos novilhos em confinamento ( 22 dias), e a maior percentagem de concentrado oferecida na dieta (56,5\% na MS), o que pode ter proporcionado maior aporte energético a este tratamento.

As percentagens de músculo obtidas mostram-se superiores aquelas obtidas por RESTLE et al. (1996), sendo o valore de 65,5\%. No entanto, MOLETTA \& RESTLE (1996) observaram valor intermediário entre TC e TS $(68,56 \%)$.

A cor e o marmoreio não foram diferentes $(\mathrm{P}=0,3813$ e $\mathrm{P}=0,1114)$ entre os tratamentos, sendo classificados em vermelho vivo e vermelho, leve mais $\mathrm{e}$ leve menos, respectivamente, para TC e TS. O maior grau de marmoreio, embora numericamente, deve-se principalmente ao maior tempo de permanência no confinamento e à maior participação energética no alimento concentrado do TC. A quantidade de gordura da carne pode estar relacionada à sua coloração, porque segundo VAZ et al. (2003), carnes mais magras tendem a ser mais escuras. Os novilhos que receberam a silagem de milho apresentaram carne com textura fina enquanto a carne dos novilhos que receberam a cana de açúcar como volumoso apresentaram textura levemente fina.

\section{CONCLUSÃO}

Novilhos alimentados com silagem de milho proporcionam melhor rendimento de carcaça fria, maior percentagem de músculo e menor de gordura na carcaça.

\section{AGRADECIMENTOS}

Amaral.

À FAPERGS, pela concessão de bolsa de pesquisa a

\section{REFERÊNCIAS}

ABAID, F.R. da C. Aspectos quantitativos e qualitativos de carcaças de novilhos abatidos em diferentes idades $e$ grupos de peso. 1981. 74f. Dissertação (Mestrado em Zootecnia) - Curso de Pós-graduação em Zootecnia, Universidade Federal de Santa Maria.

ARBOITTE, M.Z. et al. Características da carcaça de novilhos 5/8 Nelore-3/8 Charolês abatidos em diferentes estádios de desenvolvimento. Revista Brasileira de Zootecnia v.33, n.4, p.969-977, 2004.

BRONDANI, I.L. Efeito das dietas contendo cana-deaçúcar ou silagem de milho no desempenho de novilhos em confinamento e nas características de carcaça. 1989. 114f. Dissertação (Mestrado em Zootecnia) - Curso de Pósgraduação em Zootecnia, Universidade Federal de Santa Maria.

CARMO, C. de A. et al. Degradabilidade da matéria seca e fibra detergente neutra da cana de açúcar (Saccharum ssp.) com diferentes fontes de proteína. Revista Brasileira de Zootecnia, v.30, n.6, p.2126-2133, 2001.

DODE, M.A.N. et al. Estimativas dos principais cortes e da porção comestível da carcaça, em novilhos holandês PB. 
Pesquisa Agropecuária Brasileira, v.21, n.7, p.771-776, 1986.

FRANZOLIN, M.H.T. et al. Efeito de rações com níveis crescentes de cana-de-açucar em substituição à silagem de milho sobre a população de protozoários cicliados no rúmen de ovinos. Revista Brasileira de Zootecnia, v.29, n.5, p.1452-1457, 2000 .

HANKINS, O.G.; HOWE, P.E. Estimation of composition of beef carcasses and cuts. D.C.: USDA, 1946. $21 \mathrm{p}$. (Technical Bulletin, USDA n.926).

KEPLIN, L.A.S. et al. Avaliação dos aspectos quantitativos e qualitativos de carcaças de novilhos da raça charolês, abatidos com diferentes pesos. In: REUNIÃO ANUAL SOCIEDADE BRASILEIRA DE ZOOTECNIA, 1986, Campo Grande, MG. Anais... Viçosa: Soc Bras de Zootecnia, 1986. p.326.

LANA, R.P. Sistema Viçosa de formulação de rações. Viçosa: UFV, 2000. 59p.

MORAES, G.V. de. Efeito da idade de castração sobre o crescimento e características da carcaça de bovinos. 1982. 141f. Dissertação (Mestrado em Zootecnia) - Curso de Pós-graduação em Zootecnia, Universidade Federal de Santa Maria.

MULLER, L. et al. Evaluacion de técnicas para determinar la composicion de la canal. In: REUNIÃO ANUAL DA ASSOCIACCION LATINO AMERICANA DE PRODUCCION ANIMAL, 1973, Guadalajara, México. Anais... Guadalajara: Assoc. Lat. Americana de Prod. Animal. p. 73. 1973.

MULLER, L. et al. Aspectos quantitativos e qualitativos das carcaças de novilhos abatidos em três diferentes idades. In: REUNIÃO ANUAL SOCIEDADE. BRASILEIRA DE ZOOTECNIA., 17, 1980, Fortaleza. Anais... Viçosa: Soc Bras Zootec, 1980 . p.133.

MULLER, L. Normas para avaliação de carcaças e concursos de carcaças de novilhos. 2.ed. Santa Maria: UFSM, 1987. 31p.
MOLETTA, J.L., RESTle, J. Características de carcaça de novilhos de diferentes grupos genéticos terminados em confinamento. Revista da Sociedade Brasileira de Zootecnia, Viçosa, v.25, n.5, p.876-887, 1996.

PATE, F.M. Fresh Chopped sugar cane in growing-finishing steer diets. Journal of Animal Science, v.53, p.881-888, 1981 .

RESTLE, J. et al. Características de carcaça de bovinos de corte inteiros ou castrados em diferentes idades. Pesquisa Agropecuária Brasileira, v.29, n.10, p.1603-1607, 1994.

RESTLE, J. et al. Efeito de raça e heterose para características quantitativas da carcaça de novilhos de 24 meses de idade terminados em confinamento. In: REUNIÓN ALPA, 14; CONGRESSO AAPA, 19, 1995, Mar del Plata, Argentina. Anais... Mar del Plata: Revista Argentina de Produccion Animal, 1995. V.15 n.3/4, p.857-859.

RESTLE, J. et al. Características das carcaças e da carne de bovinos inteiros ou submetidos a duas formas de castração, em condições de pastagem. Revista da Sociedade Brasileira de Zootecnia, v.25, n.2, p.334-344, 1996.

RESTLE, J. et al. Características de carcaça e da carne de vacas de descarte de diferentes genótipos Charolês X Nelore, terminadas em confinamento. Ciência Rural, v.33, n.2, p.345-350, 2003.

VAZ. F.N. et al. Estudo da carcaça de bubalínos Mediterrâneos terminados em confinamento com diferentes fontes de volumoso. Revista Brasileira de Zootecnia, v.32, n.2, p.393404, 2003.

SAS INSTITUTE. SAS/STAT User's guide. Version 8.1ed. Cary, 943f. 2001.

SOUZA, J.C.D. de. Efeito do regime alimentar e tipo racial no desempenho animal e características de carcaça de bovinos. 1983. 90f. Dissertação (Mestrado em Zootecnia) Curso de Pós-graduação em Zootecnia, Universidade Federal de Santa Maria. 